\title{
CLONAGEM DE QUATRO ESPÉCIES DE Annonaceae POTENCIAIS COMO PORTA-ENXERTOS ${ }^{1}$
}

\author{
ERIVALDO JOSÉ SCALOPPI JUNIOR² \& ANTONIO BALDO GERALDO MARTINS ${ }^{3}$
}

\begin{abstract}
RESUMO - O trabalho objetivou o estudo da capacidade de enraizamento de quatro espécies de Annonaceae potenciais como porta-enxertos (Annona glabra L., Annona montana Macfad, Rollinia emarginata e Rollinia mucosa Baill.) em três épocas do ano (verão, outono e inverno). Experimento conduzido em câmara de nebulização intermitente pertencente à UNESP/FCAV (21 ${ }^{\circ} 15^{\prime} 2^{\prime \prime}$ 'S e $48^{\circ} 18^{\prime} 58^{\prime \prime}$ W), utilizando-se de estacas apicais enfolhadas em tratamento rápido (5 segundos) com ácido indolbutírico (IBA) $\left(0 ; 1000 ; 3000 ; 5000\right.$ e 7000 mg.L $\left.{ }^{-1}\right)$, em esquema fatorial. Após 90 dias, avaliaram-se a porcentagem de estacas enraizadas, sobrevivência, comprimento e número de raízes. Como resultados, o IBA não incrementou a capacidade de enraizamento das espécies. A época do ano foi grande influente no sucesso de enraizamento, sendo o verão mais adequado. A. glabra e A. montana mostraram-se promissoras na propagação vegetativa via estaquia (clonagem). $R$. emarginata apresentou baixos valores para as características avaliadas, devendo ser intensificados experimentos na promoção do enraizamento em relação aos atuais valores obtidos. $R$. mucosa não apresentou resultados satisfatórios, ocorrendo necrose de tecido na base das estacas, devendo as causas serem melhor investigadas. $\mathrm{O}$ sucesso no enraizamento de Annonaceae é dependente da espécie, tendo aquelas do gênero Annona apresentado resultados superiores em relação às do gênero Rollinia.
\end{abstract}

Termos para indexação: Annona spp., Rollinia spp., estaquia, propagação assexuada, enraizamento adventício, estações do ano, IBA.

\section{VEGETATIVE PROPAGATION OF FOUR Annonaceae ROOTSTOCKS}

\begin{abstract}
This work aimed to study the rooting capacity of four rootstocks (Annona glabra L., Annona montana Macfad, Rollinia emarginata and Rollinia mucosa Baill.) for Annonaceae species. The experiment was carried out at UNESP/FCAV (21 $1^{\circ} 15^{\prime} 22^{\prime \prime} \mathrm{S}$ and $\left.48^{\circ} 18^{\prime} 58^{\prime \prime} \mathrm{W}\right)$. Apical leafy cuttings were treated (5 seconds) with different concentrations of indolbutiric acid (IBA) $\left(0,1000,3000,5000\right.$ and 7000 mg. $\left.\mathrm{L}^{-1}\right)$. After the treatment, the cuttings were placed in drilled box supplied with vermiculite under intermitent mist inside a lathhouse. It was used experimental design completely randomized in factorial scheme. After 90 days the evaluations were made for: percentage of rooted and survived cuttings, number and length of roots. The IBA did not increase the rooting in the species. A. glabra and A. montana showed to be promising to cutting in summer. $R$. emarginata presented low values for all the evaluated characteristics and experiments must be intensified to promote the rooting. $R$. mucosa did not present satisfactory results, and the causes must be investigated better. For all the evaluated characteristics, the Annona species presented better values in relation to Rollinia.
\end{abstract}

Index Terms: Annona spp., Rollinia spp., cutting, clonal propagation, rooting, season, IBA.

\section{INTRODUÇÃO}

A pinha (Annona squamosa L.) e a atemóia (A. cherimola Mill. x A. squamosa L.) destacam-se como produtoras de frutos para consumo in natura dentre as Annonaceae. Esta última vem despertando interesse ao cultivo, devido às qualidades de fruto, principalmente para pequenas propriedades, além de ser mais uma opção de frutífera adaptada às condições climáticas do Estado de São Paulo. A graviola (A. muricata) é a anonácea com o maior potencial de industrialização, utilizada na produção de polpa, para diversas finalidades, sendo plantada em escala comercial, principalmente nos Estados da região Nordeste. Um dos principais motivos do uso de porta-enxertos nesta espécie é torná-la mais tolerante à broca do colo e propiciar melhoria da produção (Vargas Ramos, 1992). Alguns problemas iniciais no cultivo de pinha, como instalação de pomares via semente (causando alta desuniformidade) e a ausência de um adequado porta-enxerto, posteriormente também para a atemóia, causaram intensificação em experimentações na busca de espécies compatíveis (Tokunaga, 2000), tendo em vista problemas decorrentes da incompatibilidade entre as espécies-copa e alguns porta-enxertos.

As anonáceas, em geral, são muito suscetíveis às diversas podridões de raiz e colo (Kavati, 1992), além de serem atacadas por coleobrocas (Tokunaga, 2000), o que exige a utilização de porta-enxertos na tentativa de amenizar os problemas decorrentes.

A possibilidade da propagação de porta-enxertos via estaquia (Hartmann \& Kester, 1968) permite uma uniformidade do material, que futuramente constituirá o pomar comercial, além da redução do tempo de formação da muda. A propagação por estaquia pode ser influencia- da por diversos fatores (Calabrese, 1978; Menzel, 1985), entre características inerentes à própria planta e as condições do meio ambiente. Dentre os fatores que podem melhorar os resultados, destacam-se a presença de folhas na estaca, a utilização de câmara com nebulização intermitente, os reguladores de crescimento, o estádio de desenvolvimento da planta e do próprio ramo, além da época do ano em que as estacas são coletadas.

O presente trabalho teve como objetivo a propagação vegetativa (clonal) de quatro espécies de Annonaceae, potenciais como porta-enxertos, pelo processo da estaquia, em três épocas distintas (verão, outono e inverno), utilizando-se de estacas apicais enfolhadas tratadas com diferentes concentrações de Ácido Indolbutírico (IBA).

\section{MATERIALEMÉDODOS}

O experimento foi conduzido em câmara de nebulização intermitente, pertencente ao Departamento de Produção Vegetal da UNESP/ FCAV, Câmpus de Jaboticabal ( $21^{\circ} 15^{\prime} 22^{\prime \prime S}$ e $\left.48^{\circ} 18^{\prime} 58^{\prime \prime O}\right)$, sob condições de ripado, com $50 \%$ de luminosidade. O sistema de nebulização era acionado por "timer" e programado para manter uma película d'água na superfície das folhas.

Foram utilizados quatro porta-enxertos, sendo dois do gênero Annona e dois do gênero Rollinia, descritos a seguir: Annona glabra L., conhecida como anona do brejo ou anona lisa, é considerada como um porta-enxerto ananizante e indicada para áreas úmidas, por tolerar podridões radiculares; Annona montana Macfad, conhecida como falsa graviola sem ser no entanto tão suscetível ao frio como esta; Rollinia emarginata, conhecida como araticum-mirim, induz o ananismo sobre

\footnotetext{
${ }^{1}$ (Trabalho 186/2002). Recebido: 04/12/2002. Aceito para publicação: 11/07/2003. Parte da dissertação apresentada pelo primeiro autor para obtenção do título de Mestre em Agronomia no Programa de Produção Vegetal pela UNESP/FCAV. Apoio financeiro: UNESP/FCAV e CAPES.

${ }^{2}$ Mestrando, Dep. Produção Vegetal, UNESP/FCAV, Câmpus de Jaboticabal. Via de acesso Prof. Paulo Donato Castellane s/n, CEP 14.884-900, Jaboticabal, SP. Tel.: 1632092668 sjunior@fcav.unesp.br.

${ }^{3}$ Prof., Dep. Produção Vegetal, UNESP/FCAV. baldo@fcav.unesp.br.
} 
a copa de atemóia, o início da produção é antecipado em um ano quando comparada com plantas enxertadas sobre atemóias, cherimóias ou Rollinia sp., sendo indicada para solos de várzea e resistente aos fungos de solo, com o inconveniente de a plântula levar 30 meses antes da enxertia (Bonaventure, 1999); Rollinia mucosa Baill, conhecida como biribá, é encontrada em solos de várzea alta da região amazônica (Calzavara, 1980). Os porta-enxertos utilizados apresentam boa compatibilidade com as variedades copa, além de serem tolerantes à podridões de solo. Para melhor visualização e entendimento, as espécies serão denominadas como AG, AM, RE e RM, conforme descritas acima, respectivamente.

Foram coletadas estacas apicais dos ramos da parte mediana das plantas, provenientes do Câmpus da UNESP/FCAV, com cerca de $15 \mathrm{~cm}$, contendo um par de folhas desenvolvidas no nó superior, eliminando-se as folhas jovens da brotação terminal e demais folhas. Após preparadas, as estacas foram tratadas por imersão rápida durante cinco segundos em IBA, nas concentrações: 0 (testemunha); 1000; 3000; 5000 e $7000 \mathrm{mg} . \mathrm{L}^{-1}$ e estaqueadas em seguida em bandejas plásticas perfuradas, preenchidas com vermiculita de grânulos médios, mantidas na câmara de nebulização intermitente. O experimento foi realizado em três épocas, sendo a coleta de estacas realizada em 12/2000, 08/2001 e 04/2002, respectivamente, para verão, inverno e outono.

O delineamento experimental foi o inteiramente casualizado, em esquema fatorial $3 \times 4 \times 5$, com 3 épocas do ano, 4 espécies e 5 concentrações de IBA, totalizando 60 tratamentos. Cada tratamento constou de 4 repetições, sendo 15 estacas por parcela, num total de 3600 estacas.

Ao término de cada época do experimento, que ocorreu aos noventa dias, foram avaliados a porcentagem de estacas enraizadas em relação à sobrevivência, porcentagem de sobrevivência, número e comprimento médio de raízes. Os resultados foram submetidos à análise de variância, pelo teste $\mathrm{F}$, e as médias comparadas pelo teste de Tukey, sendo a transformação de dados apresentada nas Tabelas. Para efeito da análise estatística, os dados em porcentagem relativos ao enraizamento e sobrevivência foram transformados em arco-sen ( $\mathrm{x}+$ $1)^{1 / 2}$, enquanto os valores referentes ao número e comprimento de raízes foram transformados em $(\mathrm{x}+1)^{1 / 2}$.

\section{RESULTADOSE DISCUSSÃO}

A Tabela 1 apresenta o resumo dos quadros de análise de variância com os valores e significância do teste F para as características avaliadas. Os fatores época e espécie, isolados ou sua interação, apresentaram significância ao nível de $1 \%$ de probabilidade para todas as características avaliadas, mostrando serem estas dependentes da espécie a ser propagada em função da época. O fator concentração apresentou significância ao nível de $5 \%$ de probabilidade apenas para o número de raízes. Todas as outras interações não foram significativas.

Experimentos comprovam que a época de realização da estaquia interfere nos resultados obtidos em inúmeras espécies. Nachtigal et al. (1999) trabalharam com a propagação vegetativa do umezeiro e obtiveram percentuais de enraizamento de 9 a $38 \%$ no outono, enquanto Mayer et al. (2000) obtiveram de 78 a $93 \%$ na primavera com a mesma espécie. Na Itália, Tazzari et al. (1989) encontraram diferentes resultados de enraizamento entre cultivares de cherimóia, que também variaram com a época do ano, mostrando a dependência não somente da espécie em questão, mas também da cultivar a ser utilizada, indicando que o enraizamento é variável dentro de seleções ou grupos de clones para uma mesma espécie.

A Tabela 2 apresenta os valores de $\mathrm{F}$ do desdobramento da análise de variância para espécie dentro de época e época dentro de espécie. Com relação ao enraizamento, não houve diferença significativa somente para época dentro de RM, apresentando esta espécie baixos valores, independentemente da época do ano. As estacas desta espécie parecem sofrer oxidação e destruição dos tecidos da base, onde ficam em contato com a vermiculita, apesar de este substrato apresentar ótimas condições de aeração. Para sobrevivência, verifica-se significância em todos os desdobramentos. Para número de raízes, o desdobramento da espécie dentro do inverno não foi significativo, mostrando baixos valores para esta característica, independentemente da espécie para esta época do ano; como também não foi significativo o desdobramento da época dentro de RM. Para comprimento de raízes, não se constatou significância para época dentro de RE e RM; no caso da primeira espécie, nota-se que não houve influência da época no comprimento de raízes e para a última, que apresentou valores quase nulos, independentemente da época (Tabela 5).

TABELA 1 - Valores de F obtidos para os fatores época, espécie, concentração e respectivas interações em relação ao enraizamento, sobrevivência, número e comprimento de raízes. Jaboticabal, UNESP/FCAV, 2003.

\begin{tabular}{|c|c|c|c|c|}
\hline Causas de variação & Enraizamento & Sobrevivência & Número de raízes & Comprimento de raízes \\
\hline Época & $101,53 * *$ & $67,27 * *$ & $69,69 * *$ & $53,46 * *$ \\
\hline Espécie & $51,42 * *$ & $70,74 * *$ & $40,19 * *$ & $34,95 * *$ \\
\hline Concentração & $2,04^{\mathrm{ns}}$ & $2,40^{\mathrm{ns}}$ & $2,98^{*}$ & $1,01^{\mathrm{ns}}$ \\
\hline Época x espécie & $32,90 * *$ & $14,45 * *$ & $15,46 * *$ & $19,20 * *$ \\
\hline Época $x$ concentração & $0,98^{\mathrm{ns}}$ & $1,57^{\mathrm{ns}}$ & $1,11^{\mathrm{ns}}$ & $1,53^{\mathrm{ns}}$ \\
\hline Espécie $\mathrm{x}$ concentração & $0,88^{\mathrm{ns}}$ & $0,89^{\mathrm{ns}}$ & $0,66^{\mathrm{ns}}$ & $1,65^{\mathrm{ns}}$ \\
\hline Época $\mathrm{x}$ espécie $\mathrm{x}$ concentração & $1,37^{\mathrm{ns}}$ & $1,08^{\mathrm{ns}}$ & $1,17^{\mathrm{ns}}$ & $1,39^{\mathrm{ns}}$ \\
\hline C.V. $(\%)$ & 56,9 & 32,6 & 20,9 & 27,8 \\
\hline
\end{tabular}

**, ${ }^{*}$ e ${ }^{\text {ns }}$ representam significância ao nível de 1 e $5 \%$ de probabilidade e não significância, respectivamente.

TABELA 2 - Valores de F obtidos nos desdobramentos das interações espécies x época para as variáveis enraizamento, sobrevivência, número e comprimento de raízes. Jaboticabal, UNESP/FCAV, 2003.

\begin{tabular}{|c|c|c|c|c|}
\hline Causas de variação & Enraizamento & Sobrevivência & Número de raízes & Comprimento de raízes \\
\hline Espécie d. verão & $107,04 * *$ & $42,99 * *$ & $57,51 * *$ & $65,11 * *$ \\
\hline Espécie d. outono & $6,83 * *$ & $45,73 * *$ & $11,63^{* *}$ & $5,23 * *$ \\
\hline Espécie d. inverno & $3,35^{*}$ & $10,92 * *$ & $1,96^{\mathrm{ns}}$ & $3,01^{*}$ \\
\hline Época d. AG & $168,59 * *$ & $30,30 * *$ & $87,88^{* *}$ & $100,24 * *$ \\
\hline Época d. AM & $25,94 * *$ & $65,71 * *$ & $21,86^{* *}$ & $7,90 * *$ \\
\hline Época d. RE & $4,82 * *$ & $3,25^{*}$ & $6,11 * *$ & $2,78^{\mathrm{ns}}$ \\
\hline Época d. RM & $0,89^{\mathrm{ns}}$ & $11,35^{* *}$ & $0,19^{\mathrm{ns}}$ & $0,13^{\text {ns }}$ \\
\hline
\end{tabular}

**, $*$ e ${ }^{\mathrm{ns}}$ representam significância ao nível de 1 e $5 \%$ de probabilidade e não significância, respectivamente. 
As espécies não diferiram entre si em relação ao número e comprimento de raízes no inverno (Tabela 3), indicando que esta época não é adequada, apresentando os piores resultados também, no geral, para as outras características das quatro espécies (Tabela 4).

O inverno, mostrando-se desfavorável sobre a maioria dos valores apresentados em relação às outras épocas, indica que a falta de condições ambientais para estas espécies, além das condições fisiológicas, é mais importante que o fornecimento da auxina exógena, o que leva à conclusão de que há espécies onde as substâncias endógenas são adequadas pelo suprimento, principalmente através das folhas, desde que haja condições externas adequadas, e que há espécies onde, mesmo sob condições favoráveis, não enraízam, por uma possível presença de inibidores endógenos e/ou pela estrutura morfológica que dificulte o enraizamento, tanto na formação dos primórdios radiculares, quanto no seu caminhamento em direção ao exterior.
Ferreira \& Cereda (1999) obtiveram cerca de $28 \%$ de enraizamento de estacas de atemóia. Em outro experimento, os melhores resultados de enraizamento de estacas de pinha (26\%) foram obtidos com IBA (2500 a $3000 \mathrm{mg} . \mathrm{L}^{-1}$ ) e apenas $4 \%$ para a testemunha (Bankar, 1989). O presente experimento contradiz a afirmação de Casas et al. (1984), citados por Ferreira \& Cereda (1999), onde os autores afirmam que estacas de anonáceas são consideradas de difícil enraizamento; pois, considerando a época de verão, o enraizamento em relação à sobrevivência para AG foi superior a $90 \%$ com sobrevivência de cerca de 50\%; para AM, encontram-se valores próximos a $50 \%$ com sobrevivência de cerca de $80 \%$, sendo considerado baixo para RE e de difícil enraizamento, portanto, apenas para RM (Tabela 5). Do exposto, conclui-se que o sucesso no enraizamento de Annonaceae é dependente da espécie, não se podendo generalizar a afirmação de Casas et al. (1984) para toda esta família.

TABELA 3 - Médias de espécie dentro de época em relação ao enraizamento, sobrevivência, número e comprimento de raízes. Jaboticabal, UNESP/ FCAV, 2003.

\begin{tabular}{|c|c|c|c|c|}
\hline Época & Enraizamento $^{2}$ & Sobrevivência ${ }^{2}$ & Núm. de raízes ${ }^{3} /$ estaca & Compr. de raízes $^{3}$ \\
\hline Verão & $\mathrm{AG} \mathrm{82,1} \mathrm{a}$ & AM 66,0 a & $\mathrm{AG} 2,2 \mathrm{a}$ & $\mathrm{AG} 2,8 \mathrm{a}$ \\
\hline & $\mathrm{AM} \mathrm{44,3} \mathrm{b}$ & $\mathrm{AG} 48,1 \mathrm{~b}$ & AM $1,8 \mathrm{~b}$ & AM $1,8 \mathrm{~b}$ \\
\hline & RE $22,5 \mathrm{c}$ & RE $31,3 \mathrm{c}$ & RE $1,5 \mathrm{c}$ & RE $1,6 \mathrm{~b}$ \\
\hline & RM $12,5 \mathrm{c}$ & RM 20,5 c & RM $1,1 \mathrm{~d}$ & $\mathrm{RM} 1,1 \mathrm{c}$ \\
\hline Outono & $\mathrm{AG} \mathrm{24,7} \mathrm{a}$ & AG 81,9 a & $\mathrm{AG} 1,5 \mathrm{a}$ & AG 1,6 a \\
\hline & RE 23,1 a & AM 57,4 b & $\mathrm{AM} 1,4 \mathrm{a}$ & $\mathrm{RE} 1,4 \mathrm{ab}$ \\
\hline & AM 16,7 ab & RE $40,8 \mathrm{c}$ & RE 1,4 a & $\mathrm{AM} 1,4 \mathrm{ab}$ \\
\hline & $\mathrm{RM} 7,6 \mathrm{~b}$ & RM 36,7 c & RM 1,0 b & $\mathrm{RM} 1,1 \mathrm{~b}$ \\
\hline Inverno & AM 19,6 a & RE 40,8 a & AM 1,2 a & AM 1,4 a \\
\hline & $\mathrm{RE} 11,5 \mathrm{ab}$ & AM 33,6 ab & $\mathrm{RE} 1,2 \mathrm{a}$ & RE 1,3 a \\
\hline & AG $8,5 \mathrm{~b}$ & AG 24,9 bc & AG 1,0 a & $\mathrm{AG} 1,1 \mathrm{a}$ \\
\hline & $\mathrm{RM} 7,7 \mathrm{~b}$ & RM 17,8 c & RM 1,0 a & RM 1,1 a \\
\hline DMS (Tukey) & 10,94 & 11,14 & 0,24 & 0,34 \\
\hline
\end{tabular}

${ }^{1}$ Médias na coluna seguidas de mesma letra não diferem entre si, pelo teste de Tukey ( $\left.\mathrm{p}>0,05\right)$.

${ }^{2}$ Dados transformados em arco-Seno $(\mathrm{x}+1) \cdot{ }^{3}$ Dados transformados em $(\mathrm{x}+1)^{1 / 2}$.

TABELA 4 - Médias de época dentro de espécie em relação ao enraizamento, sobrevivência, número e comprimento de raízes. Jaboticabal, UNESP/ FCAV, 2003

\begin{tabular}{|c|c|c|c|c|}
\hline Espécie & Enraizamento $^{2}$ & Sobrevivência $^{2}$ & Núm. de raízes ${ }^{3} /$ estaca & Compr. de raízes $^{3}$ \\
\hline $\mathrm{AG}$ & $\begin{array}{c}\text { Verão } 82,1 \mathrm{a} \\
\text { Outono } 24,7 \mathrm{~b} \\
\text { Inverno } 8,5 \mathrm{c}\end{array}$ & $\begin{array}{l}\text { Outono 57,4 a } \\
\text { Verão 48,1 a } \\
\text { Inverno 24,9 b }\end{array}$ & $\begin{array}{l}\text { Verão } 2,2 \mathrm{a} \\
\text { Outono } 1,5 \mathrm{~b} \\
\text { Inverno } 1,0 \mathrm{c}\end{array}$ & $\begin{array}{c}\text { Verão } 2,8 \mathrm{a} \\
\text { Outono } 1,6 \mathrm{~b} \\
\text { Inverno } 1,0 \mathrm{c}\end{array}$ \\
\hline $\mathrm{AM}$ & $\begin{array}{c}\text { Verão 44,3 a } \\
\text { Inverno } 19,6 \text { b } \\
\text { Outono } 16,7 \text { b }\end{array}$ & $\begin{array}{c}\text { Outono } 81,9 \mathrm{a} \\
\text { Verão } 66,0 \mathrm{~b} \\
\text { Inverno } 33,6 \mathrm{c}\end{array}$ & $\begin{array}{c}\text { Verão } 1,8 \mathrm{a} \\
\text { Outono } 1,4 \mathrm{~b} \\
\text { Inverno } 1,2 \mathrm{c}\end{array}$ & $\begin{array}{c}\text { Verão } 1,8 \mathrm{a} \\
\text { Outono } 1,4 \mathrm{~b} \\
\text { Inverno } 1,4 \mathrm{~b}\end{array}$ \\
\hline $\mathrm{RE}$ & $\begin{array}{c}\text { Outono } 23,1 \mathrm{a} \\
\text { Verão } 22,5 \mathrm{a} \\
\text { Inverno } 11,5 \mathrm{~b}\end{array}$ & $\begin{array}{c}\text { Inverno 40,8 a } \\
\text { Outono 40,8 a } \\
\text { Verão } 31,3 \mathrm{a}\end{array}$ & $\begin{array}{c}\text { Verão } 1,5 \mathrm{a} \\
\text { Outono } 1,4 \mathrm{a} \\
\text { Inverno } 1,2 \mathrm{~b}\end{array}$ & $\begin{array}{c}\text { Verão } 1,6 \text { a } \\
\text { Outono } 1,4 \mathrm{a} \\
\text { Inverno } 1,3 \mathrm{a}\end{array}$ \\
\hline $\mathrm{RM}$ & $\begin{array}{l}\text { Verão } 12,5 \mathrm{a} \\
\text { Inverno 7,7 a } \\
\text { Outono 7,6 a }\end{array}$ & $\begin{array}{c}\text { Outono } 36,7 \mathrm{a} \\
\text { Verão } 20,5 \mathrm{~b} \\
\text { Inverno } 17,8 \mathrm{~b}\end{array}$ & $\begin{array}{c}\text { Verão } 1,1 \mathrm{a} \\
\text { Outono } 1,0 \mathrm{a} \\
\text { Inverno } 1,0 \mathrm{a}\end{array}$ & $\begin{array}{l}\text { Outono } 1,1 \mathrm{a} \\
\text { Verão } 1,1 \mathrm{a} \\
\text { Inverno } 1,0 \mathrm{a}\end{array}$ \\
\hline MS (Tukey) & 9,97 & 10,15 & 0,22 & 0,31 \\
\hline
\end{tabular}

${ }^{1}$ Médias na coluna seguidas de mesma letra não diferem entre si, pelo teste de Tukey $(\mathrm{p}>0,05)$

${ }^{2}$ Dados transformados em arco-seno $(\mathrm{x}+1) \cdot{ }^{3}$ Dados transformados em $(\mathrm{x}+1)^{1 / 2}$.

TABELA 5 - Médias das concentrações de IBA das quatro espécies de Annonaceae para as três épocas de avaliação sobre as características avaliadas, sendo enraizamento e sobrevivência (\%), comprimento (Tam R) $(\mathrm{cm})$ e número de raízes por estaca enraizada (Num R). Jaboticabal, UNESP/FCAV, 2003.

\begin{tabular}{|c|c|c|c|c|c|c|c|c|c|}
\hline \multicolumn{5}{|c|}{ Annona glabra } & \multicolumn{5}{|c|}{ Annona montana } \\
\hline & Enraizamento & Sobrevivência & Tam R & Num R & & Enraizamento & Sobrevivência & Tam R & Num R \\
\hline Verão & 94,0 & 52,7 & 7,2 & 4,1 & Verão & 48,0 & 76,3 & 2,4 & 2,3 \\
\hline Outono & 19,8 & 68,0 & 1,9 & 1,5 & Outono & 8,1 & 95,3 & 1,1 & 1,2 \\
\hline Inverno & 3,8 & 19,3 & 0,2 & 0,1 & Inverno & 14,7 & 31,3 & 1,2 & 0,5 \\
\hline \multicolumn{5}{|c|}{ Rollinia emarginata } & \multicolumn{5}{|c|}{ Rollinia mucosa } \\
\hline & Enraizamento & Sobrevivência & Tam R & Num R & & Enraizamento & Sobrevivência & Tam R & Num R \\
\hline Verão & 19,4 & 28,0 & 2,0 & 1,5 & Verão & 7,7 & 13,7 & 0,3 & 0,3 \\
\hline Outono & 15.5 & 42,0 & 1,2 & 1,2 & Outono & 2,2 & 37,3 & 0,5 & 0,1 \\
\hline Inverno & 5,9 & 41,7 & 0,9 & 0,6 & Inverno & 2,5 & 11,3 & 0,1 & 0,1 \\
\hline
\end{tabular}


Com os diferentes resultados obtidos em relação às épocas de estaqueamento, conclui-se que há um período do ano favorável à realização deste, devendo ser iniciado posteriormente ao inverno e com término anterior ao início do outono. O ideal seria realizar, dentro deste período favorável do ano, experimentos mensais para a determinação precisa do período mais conveniente à propagação por estaquia, principalmente para AG e AM, assim como realizado em seleções de goiabeira por Feldberg et al. (2000).

Em relação a época de verão, apesar do período inicial proposto de 90 dias para o enraizamento, verificou-se, no momento da avaliação, que raízes ocupavam o exterior das caixas, principalmente de $\mathrm{AG}$ e algumas de AM, que apresentavam bom enraizamento, porém estavam mortas. Diante disto, sugere-se que as estacas permaneçam sob nebulização no período de verão, por um período de 60-70 dias, para que, após, possam ser transplantadas, obtendo-se maiores índices de sobrevivência.

Para RE, devem ser realizados tratamentos alternativos, que possam incrementar as taxas de enraizamento, como retirada de estacas mais tenras, que, visualmente, apresentaram maior capacidade de enraizamento do que estacas lignificadas; tratamento das estacas com o elemento boro, promovendo a translocação de carboidratos; estiolamento dos ramos; anelamento; etc. (Hartmann \& Kester, 1968). A obtenção de um protocolo para a propagação por estaquia desta espécie é em particular desejável, por apresentar boas características como porta-enxerto e com o inconveniente de a plântula levar 30 meses até a enxertia.

Com baixo índice de enraizamento e sobrevivência apresentados para RM, devido à queimadura e necrose de tecido existente na base das estacas no momento da avaliação, independentemente da concentração utilizada, experimentos devem ser realizados na tentativa de solucionar o problema aparente.

\section{CONCLUSÕES}

1) O tratamento com IBA não promoveu incrementos no enraizamento das espécies de Annonaceae utilizadas.

2) 2. Para todas as características avaliadas, as espécies do gênero Annona apresentaram melhores resultados em relação à Rollinia.

3) O sucesso no enraizamento em Annonaceae é dependente da espécie e da época do ano, havendo, portanto, um período favorável à realização da estaquia, com as epécies $A$. glabra e A. montana comportando-se, em primeiro instante, como promissoras.

4) A espécie $R$. emarginta apresentou baixos valores para as características avaliadas, devendo ser realizados experimentos que possam incrementar os atuais valores obtidos.

5) A espécie $R$. mucosa apresentou insucesso na propaga- ção via estaquia, devendo as causas serem melhor investigadas.

\section{REFERÊNCIASBIBLIOGRÁFICAS}

BANKAR, E.J. Vegetative propagation in annonas (Annona squamosa L.). Haryana, Journal of Horticultural Sciences, v.18, n.1/2, p.1013, 1989. In: CAB Abstracts, 1990-1991. 1CD-ROM.

BONAVENTURE, L. El cultivo de la chirimoya y de su híbrido atemoya en Brasil. Acta Horticulturae, Wageningen, n.497, p.147-151, 1999.

CALABRESE, F. Frutticoltura tropicale e subtropicale. Bologna: Coop. Lib. Un. Editrice, 1978. 498p.

CALZAVARA, B.B.G. Fruteiras: abieiro, abricozeiro, bacurizeiro, biribazeiro, cupuaçuzeiro. Brasília: IPEAN, EMBRAPA - CPATU, 1980.77p. (Série Culturas da Amazônia).

FELDBERG, N.P.; NACHTIGAL, J.C.; PEREIRA, F.M. Propagação de goiabeira (Psidium guajava L.), seleção 8502-01, por meio de estacas herbáceas. In: CONGRESSO BRASILEIRO DE FRUTICULTURA, 16., 2000, Fortaleza. Resumos... Fortaleza: EMBRAPA Agroindústria Tropical/SBF, 2000. p.386. 1CD-Rom.

FERREIRA, G.; CEREDA, E. Efeito da interação entre fitorreguladores, substratos e tipos de estacas no enraizamento de atemóia (Annona cherimola Mill x A. squamosa L.). Revista Brasileira de Fruticultura, Jaboticabal, v.21, n.1, p.79-83, 1999.

HARTMANN, H,T.; KESTER, D.E. Plant propagation: principles and practices. New Jersey: Prentice Hall, 1968. 702p.

KAVATI, R. O cultivo da atemóia. In: Fruticultura Tropical. Jaboticabal: FUNEP,p.39-70. 1992.

MAYER, N.A.; NACHTIGAL, J.C.; PEREIRA, F.M. Propagação vegetativa do umezeiro (Prunus mume Sieb \& Zucc.) por estaquia herbácea em câmara de nebulização. In: CONGRESSO BRASILEIRO DE FRUTICULTURA, 16., 2000, Fortaleza. Resumos... Fortaleza: EMBRAPAAgroindústria Tropical/SBF, 2000. p.594. 1CD-Rom.

MENZEL, C.M. Propagation of lychee: a review. Scientia Horticulturae, Amsterdam, v.25, n.1, p.31- 48, 1985.

NACHTIGAL, J.C.; PEREIRA, F.M.; DALL'ORTO, F.A.C.; OJIMA, M.; MARTINS, F.C. Propagação vegetativa do umezeiro (Prunus mume) por meio de estacas herbáceas. Revista Brasileira de Fruticultura, Jaboticabal, v.21, n.2, p.226-8, 1999.

TAZZARI, L.; PESTELLI, P.; FIORINO, P.; PARRI, G. Propagation techniques for Annona cherimola Mill. Acta Horticulturae, Nelspruit, n.275, p.315-321, 1990. In: CAB Abstracts, 1993-1994. 1CD-ROM.

TOKUNAGA, T. A cultura da Atemóia. Campinas: CATI, 2000. 80p. (Boletim Técnico, 233).

VARGAS RAMOS, V.H. Cultura da gravioleira (Annona muricata L.). In: Fruticultura tropical. Jaboticabal: Funep, 1992, p.127-57. 